\title{
An aberrant mediastinal mediobasal segmental pulmonary artery in a patient with lung cancer undergoing right lower lobectomy: a case report
}

Kazuyuki Komori ( $\square$ kazooo19811227@msn.com )

NDMC: Boei lka Daigakko https://orcid.org/0000-0002-2949-2876

Hiroshi Hashimoto

Boei lka Daigakko

Kotaro Yoshikawa

Boei Ika Daigakko

Koji Kameda

Boei Ika Daigakko

Shinichi Taguchi

Boei lka Daigakko

Yuichi Ozeki

Boei Ika Daigakko

\section{Case report}

Keywords: Right aberrant mediastinal pulmonary artery, Lung cancer, Right lower lobectomy

Posted Date: September 23rd, 2021

DOI: https://doi.org/10.21203/rs.3.rs-922468/v1

License: (9) (i) This work is licensed under a Creative Commons Attribution 4.0 International License.

Read Full License 


\section{Abstract \\ Background}

A mediastinal mediobasal segmental pulmonary artery (A7) from the right main pulmonary artery is extremely rare.

\section{Case presentation:}

We have reported a case of a 71-year-old woman with aberrant A7 who underwent right lower lobectomy for lung cancer (cT1bNOM0, stage IA2). Preoperative three-dimensional computed tomography (CT) angiography revealed an aberrant mediastinal A7 from the right main pulmonary artery. Right lower lobectomy and mediastinal lymph node dissection were performed. Intraoperatively, A7 was observed between the superior and inferior pulmonary veins, and at the front of the lower bronchus near the anterior hilum. The artery was carefully dissected from the caudal side after dissection of the inferior pulmonary vein. Then, the lung parenchyma, which was within the fissure due to poor lobulation between the middle and lower lobes, was safely divided.

\section{Conclusions}

Thoracic surgeons need to evaluate CT angiography or enhanced multidetector CT carefully at preoperative conferences and always keep this anomaly in mind.

\section{Introduction}

Branching of the pulmonary artery, vein, and bronchus varies among individuals [1]. For thoracic surgeons, it is very important to preoperatively understand the anatomic abnormalities to perform safe lung resection. Here, we have reported an extremely rare case of a patient with lung cancer with right mediastinal mediobasal pulmonary artery (A7) who underwent right lower lobectomy.

\section{Case Report}

A 71-year-old woman presented to our department with a slow-growing semi-solid ground-glass nodule in the right lower lobe (S6) (Fig. 1) identified on follow-up computed tomography (CT) for oropharyngeal cancer after chemoradiotherapy. No lymph nodes or distant metastases were detected on positron emission tomography/CT. Thus, she was suspected to have primary lung cancer (cT1bN0M0, stage IA2). Preoperative three-dimensional (3D) CT angiography revealed an aberrant mediastinal A7 arising directly from the right main pulmonary artery, running between the superior and inferior pulmonary veins and progressing into the right lower lobe (Fig. 2). Lung function tests revealed a vital capacity of $2.80 \mathrm{~L}$ (115.2\% predicted), a forced expiratory volume in 1 second of $2.25 \mathrm{~L}$ (113.6\% predicted forced expiratory 
volume in 1 second), and a diffusing capacity for carbon monoxide of $13.36 \mathrm{ml} / \mathrm{min} / \mathrm{mmHg}(87.3 \%$ predicted). Video-assisted posterolateral fifth intercostal thoracotomy was performed with a small incision $(8 \mathrm{~cm})$. During surgery, the interlobular fissure between the middle and lower lobes was found to be incomplete without effusion or adhesion. An elastic hard tumor measuring $2 \mathrm{~cm}$ with little pleural change was found on the interlobar side in S6a. Aspiration cytology of the tumor revealed class $\mathrm{V}$ adenocarcinoma. As the $\mathrm{A} 7$ was located at the anterior hilum on preoperative $\mathrm{CT}$, the operative procedure was performed from the dorsal and caudal sides. First, the interlobular main pulmonary artery was exfoliated. Then, the A6 and A8-10 were dissected with ligation and autosuture, respectively, after interlobular incision between upper and lower lobes. Subsequently, the inferior pulmonary vein was dissected after division of the pulmonary ligament. The A7 was identified at the anterior hilum, running between the middle lobe pulmonary vein and the inferior bronchus (Fig. 3). Finally, an interlobar incision between the middle and lower lobes was safely made after A7 dissection with autosuture. The operative time was 153 minutes, and the total amount of blood loss was $25 \mathrm{~g}$.

The patient received pleurodesis therapy with OK-432 for prolonged air leakage on postoperative day, 8 . The chest drain was removed on postoperative day 10 , and she was discharged on postoperative day 13 . There was no evidence of recurrence at 6 months postoperatively.

\section{Discussion}

Thoracic surgeons often encounter anomalies of pulmonary arteries. Hong et al. reported that the incidence of a mediastinal basal pulmonary artery was $0.05 \%$ on both sides [2]. Moreover, in another anatomical pulmonary artery study, the A8/A9ष10 type, in which the main pulmonary artery branches to $A 8$ and $A 9810$, was observed in $90.8 \%$ cases [3]. Further, the A7a type, which branches off in front of the inferior pulmonary vein, was observed in $74.8 \%$ cases [4]. However, a mediastinal basal artery has not been reported.

Thus far, five case of right mediastinal basal pulmonary artery (Table 1) have been reported, all of which were reported from Japan due to the prominence and availability of CT. There were two cases of aberrant A7 and a case of A7a, A6-10, and A7-10 each. To the best of our knowledge, this is the first reported case of an aberrant $A 7$ that independently branched off during right lower lobectomy. Aberrant vessels were identified in all six cases, including our case, in which preoperative multidetector CT and 3D-CT angiography were performed. Intraoperative findings identified poor lobulation in all cases. Operative procedures can be classified depending on whether interlobular incision or resection of an aberrant artery was first performed. In three of four cases in which the pulmonary artery in the lower lobe was resected, interlobular incision of the aberrant artery was performed. In our case, we first transected the inferior pulmonary vein with autosuture from the dorsal side for better visualization of the hilum. Then, we exfoliated the aberrant A7 and transected it with autosuture. An interlobular incision between the middle and lower lobes was safely made, and the lower bronchus was transected. We had no problem with dissection of lymph node 7. So far, formation of a thrombus in the peripheral stump of the pulmonary artery has not been detected. 
It is important to check vessel variation by 3D-CT angiography and discuss the safe operative procedure at the preoperative conference.

\section{Conclusion}

In summary, we have reported a case of a patient with lung cancer and a mediobasal mediastinal pulmonary artery arising from the main pulmonary artery who underwent right lower lobectomy. Our report suggests that attention should be paid to these anomalies.

\section{Declarations}

Acknowledgements We thank Editage (https://www.editage.jp/), for editing a draft of this manuscript.

\section{Author's contributions}

KK drafted the manuscript. All authors participated in the treatment, contributed to the development of methodology, read and approved the final manuscript.

\section{Funding}

The authors have not declared funding for this study.

\section{Availability of data and materials}

Please contact us for data requests.

\section{Ethics approval and consent to participate}

Not applicable.

\section{Consent for publication}

Informed consent of clinical detail and image publication was obtained from the patient.

\section{Competing interests}

The authors declare that they have no competing interests.

\section{Author details}

${ }^{1}$ Departmant of Thoracic Surgery, National Defense Medical College, 3-2, Namiki, Tokorozawa, Saitama 359-8513, Japan. ${ }^{2}$ Department of Thoracic Surgery, Tokorozawa-Meisei Hospital, 5095, Yamaguchi, Tokorozawa, Saitama 359-1145, Japan.

\section{References}


1. Nakamura A, Watanabe SI, Watanabe Y, Asakura K, Nakagawa K. En bloc upper and lower lobe trisegmentectomy facilitated by displaced segmental airway. Ann Thorac Surg. 2017;104:e447-9.

2. Hong JH, Kim HJ, Han DH, Sung SH, Ahn Ml, Jung Jl. Arteria praebronchialis found on MDCT: potentially dangerous aberrant artery supplying the left lower lobe. Surg Radiol Anat. 2015;37:10216.

3. Yamashita H. Roentgenologic Anatomy of the lung. New York: Inc. Tokyo: Igaku-Shoin Ltd. \& IgakuShoin Medical Publishers; 1978. pp. 70-90.

4. Nagashima T, Shimizu K, Ohtaki Y, Obayashi K, Nakazawa S, Mogi A, et al. Analysis of variation in bronchovascular pattern of the right middle and lower lobes of the lung using three-dimensional CT angiography and bronchography. Gen Thorac Cardiovasc Surg. 2017;65:343-9.

5. Yamada S, Inoue Y, Suga A, Iwazaki M. Surgical risk of vessel injury: an unusual anatomical variant of the right medial basal segmental pulmonary artery. Gen Thorac Cardiovasc Surg. 2011;59:301-3.

6. Atari $\mathrm{M}$, Nakajima $\mathrm{Y}$, Fukuhara $\mathrm{M}$, lijima $\mathrm{Y}$, Kinoshita $\mathrm{H}$, Akiyama $\mathrm{H}$, et al. Abnormal branch of right pulmonary artery (A7): a case report and literature review. Surg Case Rep. 2016;2:16.

7. Kawai N, Kawaguchi T, Yasukawa M, Tojo T. Lobectomy for a mediastinal basal pulmonary artery. Gen Thorac Cardiovasc Surg. 2017;65:422-4.

8. Nakamura A, Okumura Y, Hashimoto M, Kondo N, Shibata E, Kijima T, et al. Right lower lobectomy for an aberrant mediastinal inferior lobar artery. Ann Thorac Surg. 2020;109:e415-7.

9. Takase $Y$, Tsubochi H, Yamaki E, Kawashima O. An aberrant mediastinal medial basal segmental pulmonary artery (A7a) in a patient with lung cancer: a case report. Surg Case Rep. 2021;7:21.

\section{Tables}

Due to technical limitations, Table 1 is only available as a download in the Supplemental Files section.

\section{Figures}




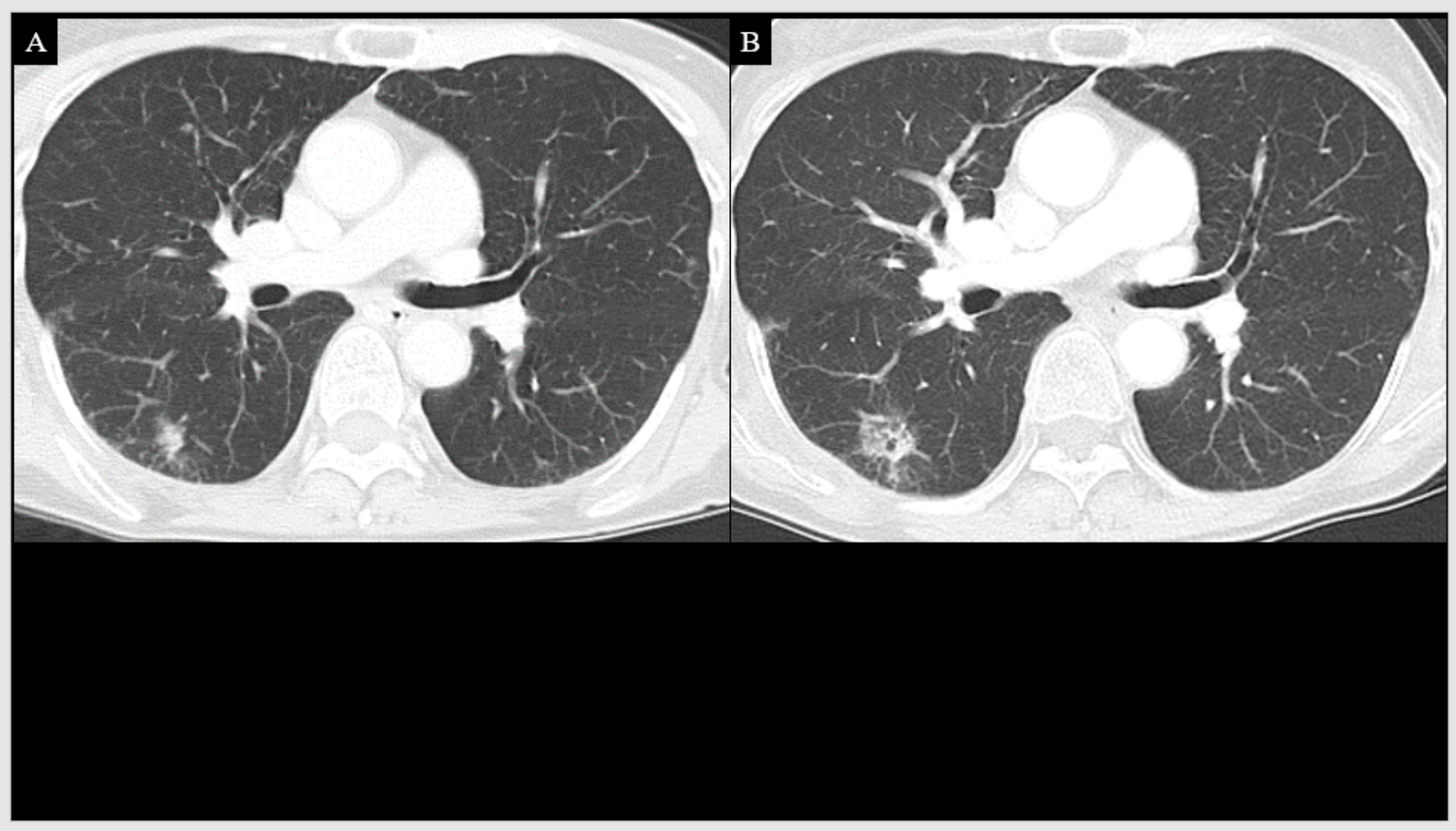

Figure 1

Chest computed tomography. (A) Semi-solid ground-glass attenuation (GGA) in the right lower lobe (B) A slow-growing GGA in 1.5 years
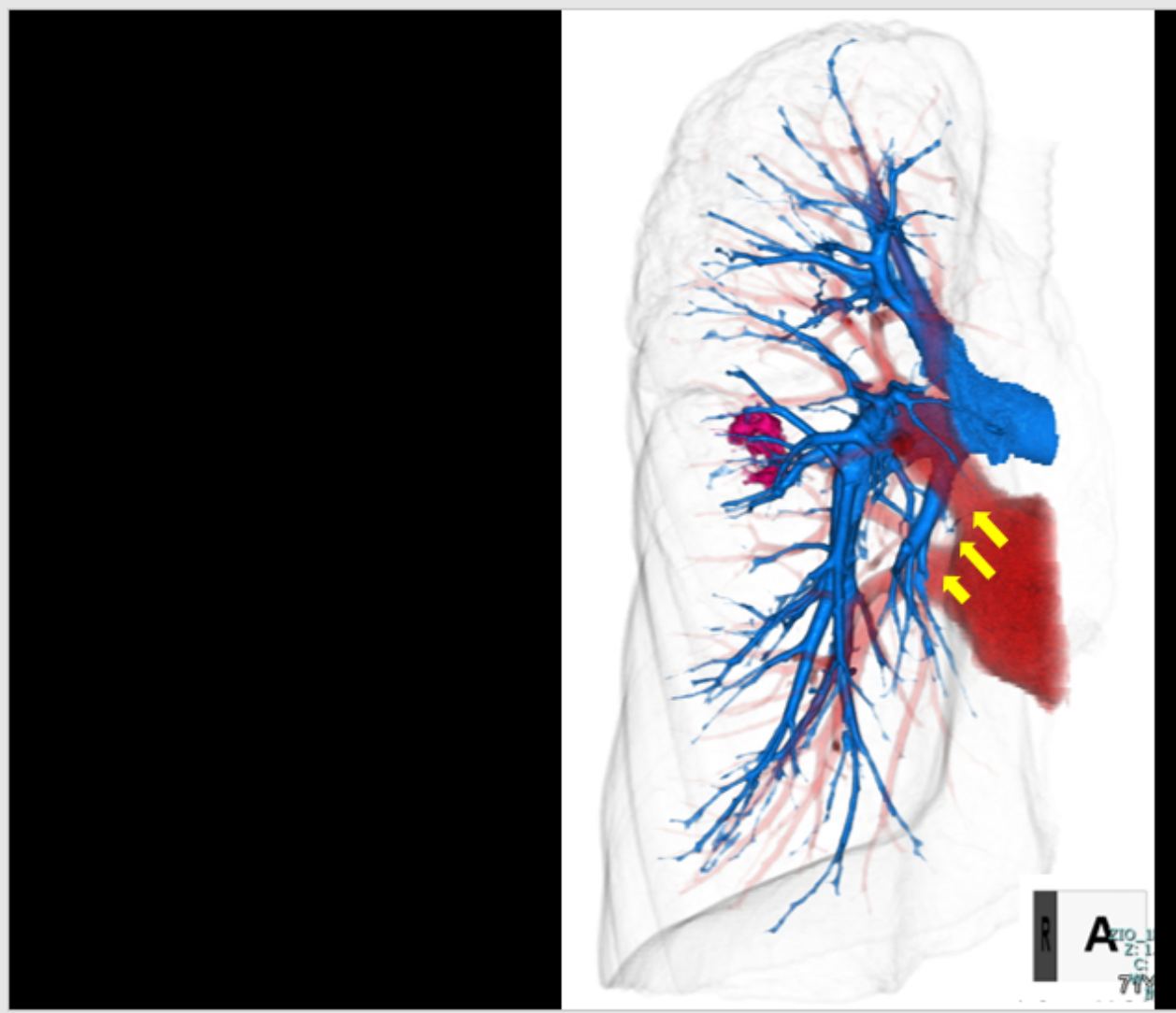


\section{Figure 2}

Preoperative three-dimensional computed tomography angiography of the right lung revealing an aberrant mediastinal A7 (yellow arrow) arising directly from the right main pulmonary artery (blue vessel) on the opposite side of $A 1 \otimes 2 a \varangle 3$, the first branch of the pulmonary artery, running between the superior and inferior pulmonary veins (red vessel) and progressing into the medial portion of the right lower lobe

\section{Figure 3}

Intraoperative finding from the caudal side after resection of inferior pulmonary vein (IPV). An aberrant A7 is seen running from the hilum between IPV stump and superior pulmonary vein (SPV)

\section{Supplementary Files}

This is a list of supplementary files associated with this preprint. Click to download.

- Table.xlsx

- CareChecklistJCTSComplete.pdf 